\title{
Review
}

\section{Recent Development of 3-Deoxyosone Related Maillard Reaction Products}

\author{
Fumitaka HAYASE \\ Meiji University, Department of Agricultural Chemistry, 1-1-1 Higashi-mita, Tama-ku, Kawasaki, Kanagawa 214-8571, Japan
}

Received January 13, 2000; Accepted March 22, 2000

\begin{abstract}
Maillard reaction occurs extensively in food systems and in vivo. In an intermediate Maillard reaction of proteins with glucose, 3-deoxyglucosone (3DG) was generated from Amadori compounds in an early stage, leading to generation of advanced glycation endproducts (AGEs). 3DG modified lysine residues to form pyrrole aldehydes (lysyl-pyrraline), and arginine residues to form imidazolone compounds, and is speculated to be a cross-linker responsible for the polymerization of proteins. 3DG is also thought to be related to the evolution of fluorescence during Maillard reaction. The fluorescent compound has been identified as lysyl-pyrropyridine which is formed by the loss of five molecules of water from the reaction between 2 molecules of lysine residues and 2 molecules of 3DG. In the protein-glucose and pentose reaction systems, crossline and pentosidine have reportedly been formed as fluorescent and crosslinking compound, respectively, as well as pyrropyridine. Immunochemical and chemical methods have clearly indicated the progressive accumulation of AGEs in tissue proteins in aging. In diabetes, AGE accumulation in general is accelerated and linked to arteriosclerosis, nephropathy, neuropathy, retinopathy, and cataract. 3DG, which has weaker mutagenicity, reacted readily with $2^{\prime}$-deoxyguanosine in nucleosides. Two major products (G-A and G-B) were isolated, and G-A was identified as $N$-(1-0xo-2,4,5,6-hydroxyhexyl)-2'-deoxyguanosine. G-B was identified as a diastereomer of G-A. Blue pigment was isolated from the reaction between D-xylose and glycine. Blue pigment which was designated Blue-M1 (blue Maillard reaction intermediate-1) was identified as novel pyrrolopyrrolylium compound and is assumed to be a dimer of yellow colored pyrrolopyrrole-2-carboxaldehyde compounds. Blue-M1 that reacts readily to yellow compounds has a polymerizing activity, suggesting that it is an important Maillard reaction intermediate through the formation of melanoidins. Melanoidins have many positive physiologic effects.
\end{abstract}

Keywords: Maillard reaction, advanced glycation endproducts, 3-deoxyglucosone, glycation, pyrropyridine, imidazolone, pyrraline, melanoidin

Typical nonenzymatic reaction occurring among food components is caused by amino and carbonyl compounds, called amino-carbonyl, carbonyl-amine, non-enzymatic browning reactions and so on. Maillard reaction originally meant the reaction between amino compounds and reducing sugars but has recently been used as a synonym for amino-carbonyl reaction. Maillard reaction, non-enzymatic glycosylation relevant to proteins is called glycation.

Amino compounds involved in the Maillard reaction in food and biological systems are amines, amino acids, peptides, proteins, base in nucleic acids, phospholipids and so on. Reducing sugars, aldehydes, ketones, polyphenols, ascorbic acid, steroids and so on are involved in this reaction as carbonyl sources.

Various phenomena and physiologic effects are caused by the Maillard reaction (Hayase \& Kato, 1994; Hayase, 1996; Friedman, 1996). In food systems, low-molecular weight products contribute to discoloration, the generation of aroma, formation of mutagens, scavenging and generation of active oxygen species, the decrease in nutritional value and digestibility. High-molecular weight products, so-called melanoidins, are involved in discoloration, antioxidative effects, scavenging on active oxygen species, antimicrobial action, desmutagenic effects and dietary fiber-like effects.

Thus, the Maillard reaction in food systems has both desirable

E-mail: fumi@isc.meiji.ac.jp and undesirable effects. We should control its effect in processing and storage of foods.

Most proteins in vivo are nonenzymatically glycated. Reducing sugars can react with amino compounds to form a Schiff base adduct which is then stabilized by an Amadori rearrangement. This reaction represents the early stage of the Maillard reaction. The reaction is followed by the intermediate stage on the generation of $\alpha$-dicarbonyls such as 3-deoxyosones, osones, methylglyoxal, and glyoxal. Furthermore, in the advanced stage of Maillard reaction, proteins are modified by advanced glycation endproducts (AGEs) with the evolution of fluorescence, browning, polymerization and degradation.

In biological systems, Maillard reaction is believed to contribute to yellowing and cross-linking of long-lived proteins such as lens crystallins, and collagen and to an array of biochemical and biological abnormalities in diabetes and aging such as stiffening of arteries and joints, increased blood pressure, and altered protein and cell turnover (Ledl \& Schleicher, 1990; Monnier et al., 1991; Cerami, 1994). Such general AGE accumulation is accelerated and linked to arteriosclerosis, nephropathy, neuropathy, retinopathy, and cataract.

Recent progress on 3-deoxyosone related AGEs in the food system and in vivo is reviewed in this paper.

1. Generation of 3-deoxyosones in Maillard reaction Lysozyme used as a model protein was reacted with reducing 
sugars in a powder state at $50^{\circ} \mathrm{C}$ and $75 \%$ relative humidity $(\mathrm{RH})$ (Cho et al., 1986; Kato et al., 1987a) under a physiologic condition of $37^{\circ} \mathrm{C}$ at $\mathrm{pH} 7.4$ (Shin et al., 1988). The results by Kato's group in the powder state revealed that the modification of amino group with glucose is an initial step and that arginine or tryptophan residues are secondarily attacked by $\alpha$-dicarbonyls formed from a medium stage of glycation. These reactive $\alpha$-dicarbonyls are thought to be liberated from lysine residues, N-terminal amino groups via the enolization of Amadori compounds, or by glucose oxidation (Wells-Knecht et al., 1995). In a lysozyme-glucose or fructose system under physiologic conditions, 3-deoxyglucosone (3DG) was formed as the major carbonyl compound (Shin et al., 1988). In addition, 3-deoxyxylosone is also formed from the lysozyme-reducing sugar reaction systems (Arai et al., 2000). Thus, 3-deoxyosones are exceedingly important on AGEs formation. 3DG has been reported to be generated in vivo (Hayase et al., 1991; Knecht et al., 1992; Niwa et al., 1993; Yamada et al., 1994) and from fructose 3-phosphate in the lens of diabetic rats (Szwergold et al., 1990). Recently, Niwa (1999) reviewed metabolism, analysis, biological activity, and clinical implications of 3-deoxyglucosone.

As are other $\alpha$-dicarbonyls, Ledl and Schleicher (1990) reported that 1-deoxyglucosone (1DG) and 4-deoxyglucosone (4DG) may also be formed during Maillard reaction. They indicate that the 2,3-enolization of an Amadori compound could also give rise to a 1,4-dideoxy-2,3-dicarbonyl derivative that remains attached to the amino group. In addition, glyoxal also has been

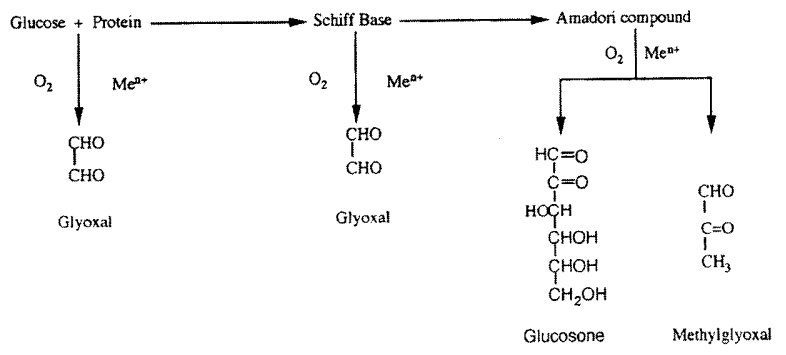

Fig. 1. Dicarbonyls formed by oxidative Maillard reaction.

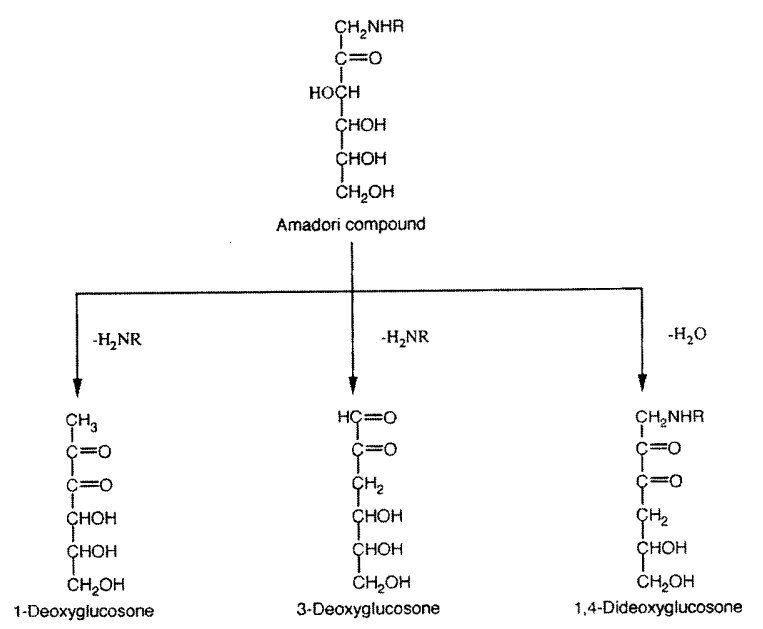

Fig. 2. Dicarbonyls formed by non-oxidative Maillard reaction. generated by glucose oxidation or the Namiki-pathway (Namiki, 1988). Methylglyoxal might be formed from Amadori compounds via 1-deoxyosone by oxidative and non-oxidative routes (Arai et al., 2000). Figures 1 and 2 show $\alpha$-dicarbonyls formed in glycated proteins during oxidative and non-oxidative Maillard reactions, respectively.

Our recent research revealed that the formation of 3DG was more significantly increased under anaerobic, than under aerobic conditions (Hayase et al., 1996). Moreover, browning, the generation of fluorescence, and polymerization were also accelerated more under anaerobic than aerobic conditions.

\section{Advanced glycation endproducts \\ 2-1. Pyrraline}

3DG is dehydrated to form 5-hydroxymethylfurfural (HMF), especially in acidic foods (Hodge, 1953), and $N$-substituted pyrrole-2-aldehydes called pyrraline are formed from 3DG and amino compounds in most foods at weakly acidic to neutral $\mathrm{pH}$ (Hayase \& Kato, 1985; Hayase \& Takahashi, 1996). $\varepsilon$-(2-formyl5-hydroxymethyl-pyrrol-1-yl)-L-norleucine (lysyl-pyrraline) was detected in browning foods since $\varepsilon$-amino group has a high reactivity to 3DG (Nakayama et al., 1980; Chiang, 1988).

The authors detected protein-bound pyrraline in serum albumin by immunological methods (Hayase et al., 1989a). The amount of the pyrraline in diabetic serum albumin increased 1.6fold compared with that in control subjects. Highly specific pyrraline immunoreactivity was detected in sclerosed glomeruli from diabetic and old normal kidneys as well as in renal arteries with arteriosclerosis (Miyata \& Monnier, 1992). The preferential

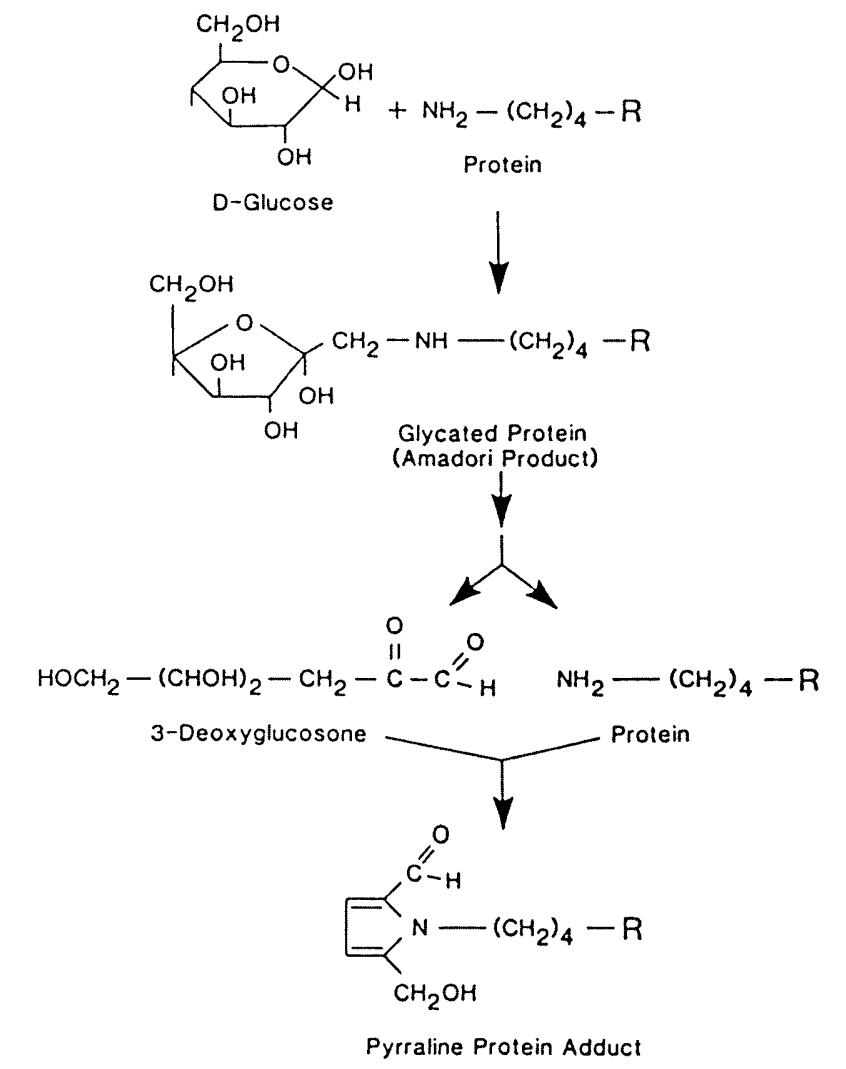

Fig. 3. Proposed mechanism of formation of protein-bound lysyl-pyrraline. 
localization of pyrraline immunoreactivity in the extracellular matrix strengthens the notion that the advanced glycation may contribute to decreased turnover and thickening of the extracellular matrix in diabetes and aging (Miyata \& Monnier, 1992).

To investigate the mechanism of the formation of proteinbound pyrraline, bovine serum albumin (BSA) was incubated with $50 \mathrm{~mm}$ glycated lysine and 3DG. At pH 7.4, similar kinetics were noted for both precursors, glycated lysine and 3DG, with

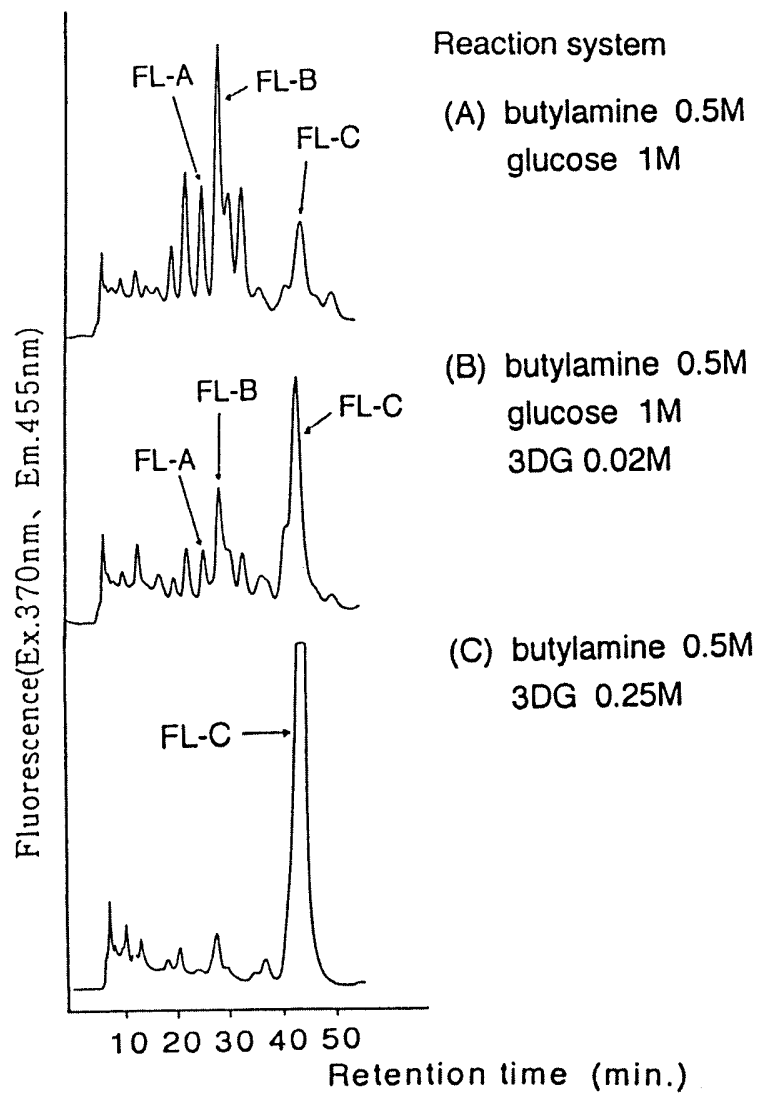

Fig. 5. HPLC patterns of reaction mixtures obtained from various Maillard reaction systems with n-butylamine at $\mathrm{pH} 7.4$ and $50^{\circ} \mathrm{C}$ for $48 \mathrm{~h}$. approximately a 10-day delay until a sharp increase of pyrraline occurred. This suggests that pyrraline formation from 3DG is the rate-limiting step in the reaction of BSA with glycated lysine. The ability of both glycated lysine and 3DG to form proteinbound pyrraline suggests a synthetic pathway whereby glycated lysine is first generated from glucose and subsequently degraded into 3DG. 3DG then reacts again with free amino groups to form pyrraline (Hayase et al., 1989a) as shown in Fig. 3. Proteinbound pyrraline has also been detected in human plasma proteins (Portero-Otin et al., 1995), and in food proteins (Henle \& Klostermeyer, 1993; Resmini \& Pellegrino, 1994).

\section{2-2. Fluorescent compounds}

In the advanced stage of Maillard reaction in vitro, fluorescent compound (Peak L1) was detected in protein hydrolysates of BSA with glucose (Kato et al., 1989). The height of Peak L1 increased with glucose concentration and incubation time.

From the results of in vivo experiments with rats, the level of Peak L1 increased with aging to reach maximum at 90 weeks of age and remained at this level until 120 weeks of age. This peak is useful as an indicator for evaluating the progress of the advanced stage reaction. Figure 4 shows the high-performance liquid chromatography (HPLC) pattern of the hydrolysate of lysozyme incubated with 3DG. Peak L1 was also found in the reaction system and increased with incubation time.

We have examined the detection of fluorescent compounds<smiles>CC(C)(C)CN1CCN(C(=O)c2ccccc2)c2cc(C(O)C(O)C(O)CO)cc1c2</smiles>

FL-A,B (crossline)<smiles>CCCCN1c2cc(C(=O)O)ccc2C2(O)CC(C(O)CO)OC12</smiles>

FL-C (butyl-pyrropyridine)
Fig. 6. Structures of FL-A and FL-B (butyl-crossline), and FL-C (butylpyrropyridine). " : asymmetric carbon.
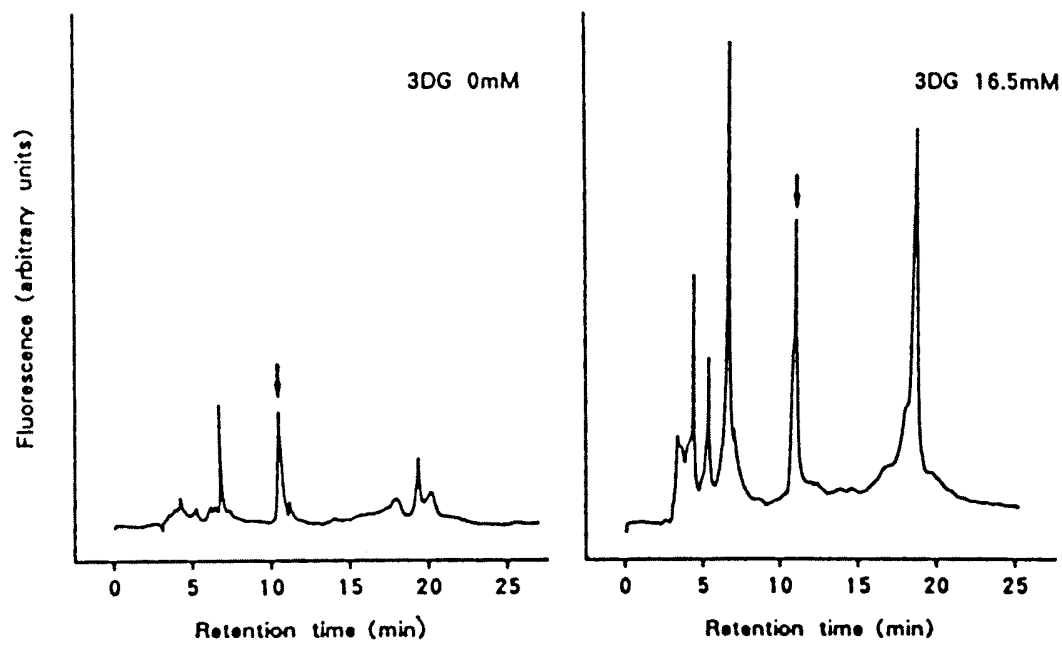

Fig. 4. HPLC of Peak L1 (arrows) in the hydrolysate of lysozyme $(10 \mathrm{mg} / \mathrm{ml})$ incubated with 3-deoxyglucosone ( 0 and $16.5 \mathrm{~mm})$ in phosphate buffer (pH 7.4) at $37^{\circ} \mathrm{C}$ for 28 days. 
formed by the reaction of lysine residues with glucose (Hayase $e t$ al., 1994). The results of HPLC analysis showed that the major three fluorescent compounds (FL-A, FL-B, FL-C) were produced in a butylamine-glucose reaction system under physiological conditions of $37^{\circ} \mathrm{C}$ at $\mathrm{pH} 7.4$ as shown in Fig. 5. FL-A and FL-B were identified as epimers of butyl-crossline, similar to compounds reported by Nakamura et al. (1992). FL-C was purified from the butylamine-3DG reaction system and identified as a pyrrolopyridinium compound called butyl-pyrropyridine (Hayase et al., 1994) as shown in Fig. 6. Lysyl-pyrropyridine was also identified by acid hydrolysis of $N^{\alpha}$-acetyllysyl-pyrropyridine which was obtained from the reaction between $\mathrm{N}^{\alpha}$-acetyllysyine and 3DG. The lysyl-pyrropyridine (Fig. 7) is formed by the loss of five molecules of water from the reaction between 2 molecules of lysine residues and 2 molecules of 3DG. The recovery of lysyl-pyrropyridine was $26.7 \%$ after acid hydrolysis. However, the lysyl-crossline appears to have decomposed in this process (Hayase et al., 1998); consequently, the findings suggest that Peak L1 may be lysyl-pyrropyridine.

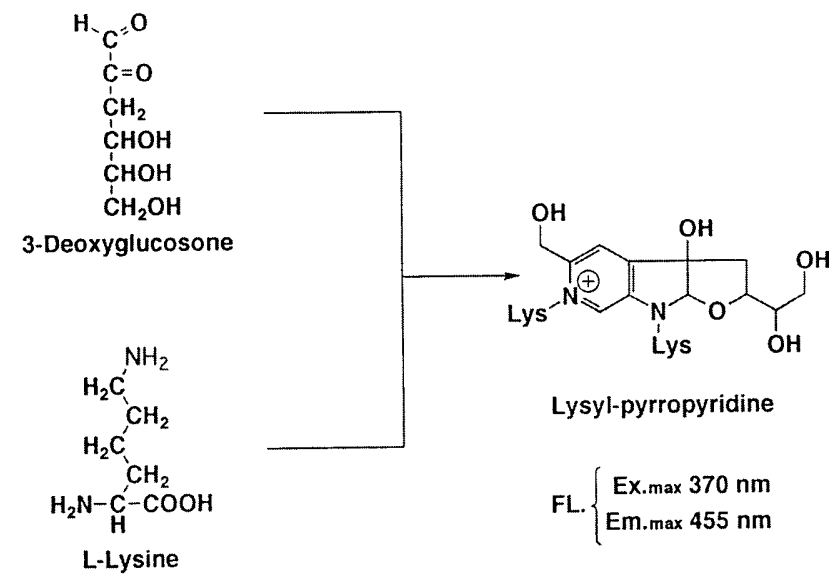

Fig. 7. The formation of lysyl-pyrropyridine from 3-deoxyglucosone and L-lysine reaction system.

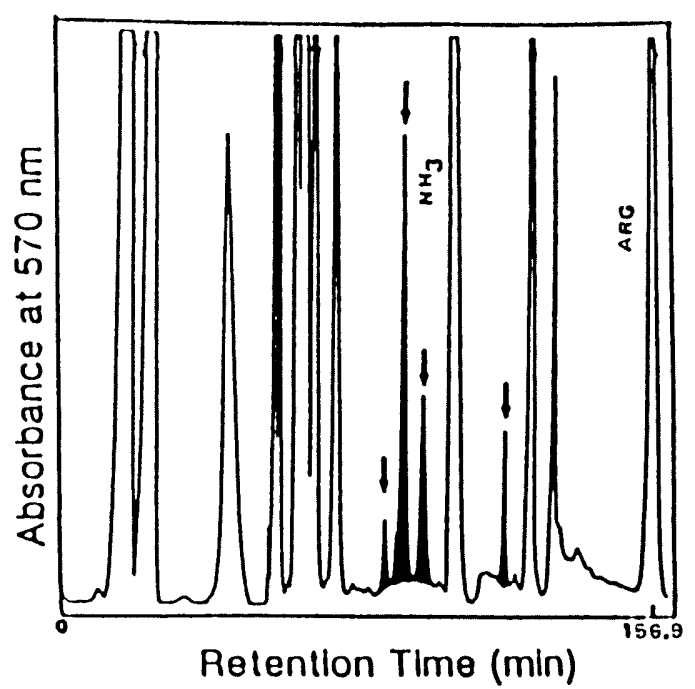

Fig. 8. Pattern of unknown peaks in the amino acid chromatogram of acid hydrolysate of lysozyme incubated with 3 -deoxyglucosone in $0.1 \mathrm{M}$ sodium phosphate buffer ( $\mathrm{pH} \mathrm{7.4)}$ at $50^{\circ} \mathrm{C}$ for 4 days.
Monnier's group identified the fluorescent compound, which was formed from pentose, arginine, and lysine, as pentosidine having an imidazorium ring (Sell \& Monnier, 1989). They mentioned that the compound was extensively distributed in vivo and increased with aging and diabetes, especially uremia (Monnier $e t$ al., 1992). Pentosidine can be formed from several carbonyl compounds such as hexoses and ascorbic acid under oxidative conditions (Grandhee \& Monnier, 1991; Dyer et al., 1991), and in vivo studies suggest that a common intermediate involving a pentose is a necessary precursor molecule. Pentosidine was also formed by 3DG-lysozyme reaction process (Hayase et al., 1998).

Pentosidine has fluorescence at $\mathrm{Ex}=335 \mathrm{~nm}$ and $\mathrm{Em}=385$ $\mathrm{nm}$, pyrropyridine at $\mathrm{Ex}=370 \mathrm{~nm}$ and $\mathrm{Em}=455 \mathrm{~nm}$, and crossline at $E x=379 \mathrm{~nm}$ and $E m=463 \mathrm{~nm}$, respectively. Accordingly, fluorescence $(\mathrm{Ex}=370 \mathrm{~nm}, \mathrm{Em}=440 \mathrm{~nm})$ observed in collagen in vivo which increases with aging and diabetes, is considered to depend on pyrropyridine and crossline but not pentosidine.

Recently lysyl-pyrropyridine was detected in the acid hydrolysates of normal aged, cataractous, diabetic and brunescent human lens proteins as well as in the acid hydrolyzed glycated hemoglobin $\mathrm{A}_{0}$ (Prabhakaram \& Mossine, 1998). They reported that a

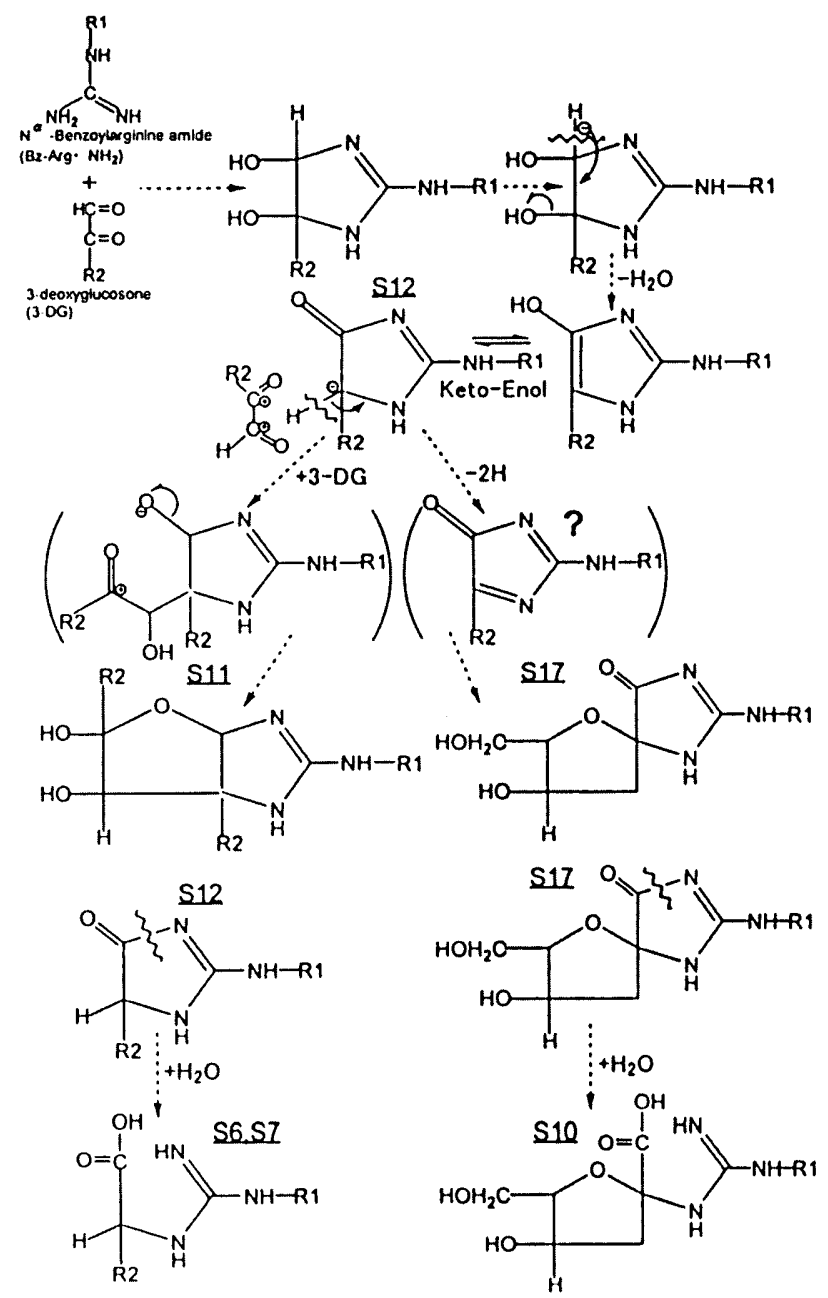

Fig. 9. Proposed formation pathway for products from the reaction between $N^{\alpha}$-benzoylarginine amide and 3-deoxyglucosone. $\mathrm{R} 1=\left(\mathrm{CH}_{2}\right)_{3} \mathrm{CH}\left(\mathrm{NHCOC}_{6} \mathrm{H}_{5}\right) \mathrm{CONH}_{2}, \mathrm{R} 2=\mathrm{CH}_{2}(\mathrm{CHOH})_{2} \mathrm{CH}_{2} \mathrm{OH}$. 
2.5-fold excess of pyrropyridine was observed in 60 year normal lens over 40 year normal lens. The pyrropyridine content was similar ( 16 nmols/mg) in age-matched (60 years) normal, cataractous, and diabetic lens, but almost double $(30.2 \mathrm{nmol} / \mathrm{mg})$ in 60 year brunescent lens.

\section{2-3. Arginine adducts modified with 3-deoxyglucosone}

As mentioned above, the polymerization of proteins occurred in the presence of reducing sugars under a physiologic condition as well as under conditions of food processing, storage, and cooking. In order to elucidate the cross-linking compounds of proteins by Maillard reaction, glycated lysozyme was hydrolyzed with $6 \mathrm{M} \mathrm{HCl}$ in evacuated tubes at $110^{\circ} \mathrm{C}$ for $24 \mathrm{~h}$. Impaired amino acid residues were lysine, arginine, and tryptophan, as described above. Unknown peaks on an amino acid chromatogram of acid hydrolysates of proteins were detected in the glucoselysozyme reaction systems and acetylated lysozyme incubated glucose and free lysine (Cho et al., 1986; Kato et al., 1987a). These peaks were identical to those detected in the lysozyme3DG reaction system as well as human serum albumin, BSA, ovalbumin, RNase A, and IgG-3DG reaction systems, respectively (Kato et al., 1987b). These results indicate that the unknown peaks originated from the impaired Arg and/or Trp residues but not from Lys residues. We then compared the amino acid chromatograms of acid hydrolysates of proteins in the lysozyme3DG system with those on the $N^{\alpha}$-benzoylarginine amide-3DG reaction system shown by arrow in Fig. 8 (Konishi et al.,1994). Findings suggested that 3DG modified arginine residues and generated unknown peaks by acid hydrolysis of lysozyme incubated with glucose.

Seventeen compounds were observed on a HPLC chart obtained from the $N^{\alpha}$-benzoylarginine amide-3DG reaction system, and are called S1 to S17. These compounds were collected and subjected to fast atom bombardment-mass spectrometry (FABMS). FAB-MS data showed that major compounds were formed from one molecule of $N^{\alpha}$-benzoylarginine amide and one (for S6, S7, S10, S12, and S17) or two (for S11) molecules of 3DG. The proposed formation scheme for these products from $N^{\alpha}$-benzoylarginine amide-3DG reaction system is indicated in Fig. 9 (Hayase et al., 1997; Hayase et al., submitted). S17, imidazolone compound, is formed via S12 by dehydration and oxidation from the above reaction system to be the major pathway. In this review, the structure of $S 17$ reported by Hayase et al. (1997) is corrected as shown in Fig. 9 as well as the structure of S6, S7, and S10. A novel spiro compound, S17, was formed by intramolecular cyclization of dehydrogenated S12. S12, imidazoline-4one compound, was also identified in a $3 \mathrm{DG}$-insulin reaction system by ESI-MS (Hayase et al., 1998).

S11 was identified as 2-( $N^{\alpha}$-benzoyl- $N^{\hat{b}}$-ornithylamide)-5,6a$\operatorname{di}(2,3,4$-trihydroxybutyl)-5,6-dihydroxydehydrofuro[2,3- $d]$ imi-

Table 1. Amounts of pyrraline, imidazolone, lysyl-pyrropyridine, and pentosidine in soy sauce (Koikuchi).

\begin{tabular}{llc}
\hline Soy sauce sample & \multicolumn{1}{c}{ AGE } & $\begin{array}{c}\text { Amount (nmol/g soy } \\
\text { sauce powder) }\end{array}$ \\
\hline Total soy sauce & Pyrraline & 3.6 \\
Total soy sauce & Imidazolone & 53.8 \\
Nondialyzable fraction ${ }^{(i)}$ & Lysyl-pyrropyridine & 2.1 \\
Nondialyzable fraction ${ }^{a)}$ & Pentosidine & 0.7 \\
\hline${ }^{(1)}$ cut molecular weight $=500$ & &
\end{tabular}

dazole. Since S11 which is formed from one molecule of $N^{\alpha}$ benzoylarginine amide and two molecules of 3DG, increased and then decreased with reaction time, it is speculated that $\mathrm{S} 11$ participated in further reactions such as the formation of cross-links.

Niwa et al. (1997a) reported that amyloid $\beta_{2}$-microglobulin is modified with imidazoline-4-one (S12) in human dialysis-related amyloidosis by immunohistochemistry using anti-S12 monoclonal antibody. S12 is also detected in kidneys and aortas of diabetic patients (Niwa et al., 1997b) and at high levels in kidneys of rats with streptozotocin-induced diabetes (Niwa et al., 1997c).

\section{2-4. AGEs in foods}

The Maillard reaction products Amadori compounds, $\alpha$-dicarbonyls, furans, pyrralines, and melanoidins are contained in roasted foods such as meats and fish, browned confectionery: toast, crackers, and potato chips, and luxury food and seasonings: muscovado, cane sugar, coffee, beer and tomato paste (Hayase \& Kato, 1994). Amadori compounds and AGEs as pyrralines and melanoidin-like brown pigments could be partly bound to food proteins. We found also pyrraline and imidazolone by immunochemical detection, and lysyl-pyrropyridine and pentosidine by HPLC after acid hydrolysis in soy sauce, respectively. Table 1 shows the amounts of these AGEs in soy sauce (Hayase et al., submitted).

\section{2-5. Modification of 2 -deoxyguanosine with 3-deoxygluco- sone}

$\alpha$-Dicarbonyls have been reported to be cytotoxic compounds (Shinoda et al., 1994). Our studies have shown that 3DG has inhibitory effects on the progression during the $\mathrm{S}$ phase in $3 \mathrm{Y} 1$ cells. Együd and Szent-Györgyi (1966) and Szent-Györgyi et al. (1967) demonstrated that methylglyoxal (MG) could efficiently inhibit cell growth. $N^{2}$-(1-carboxyethyl)guanine was identified as a guanine AGE by the nucleophilic addition of the primary amino group of guanine to the ketone group of $\mathrm{MG}$ followed by an intramolecular rearrangement (Papoulis et al., 1995).

We have investigated the mutagenicity and reactivity with nucleosides of 3DG (Hayase \& Kaneko, 1998). 3DG has weaker mutagenicity than methylglyoxal by the Ames test; it reacted readily with 2 '-deoxyguanosine $(\mathrm{dG})$ in nucleosides. Two major products (G-A and G-B) were isolated and purified from the reaction mixture of $50 \mathrm{mM} 3 \mathrm{DG}$ and $50 \mathrm{mM} \mathrm{dG}$ at $50^{\circ} \mathrm{C}$ and $\mathrm{pH}$ 7.4 for 6 days. G-A was identified as $N$-(1-oxo-2,4,5,6-hydroxy-

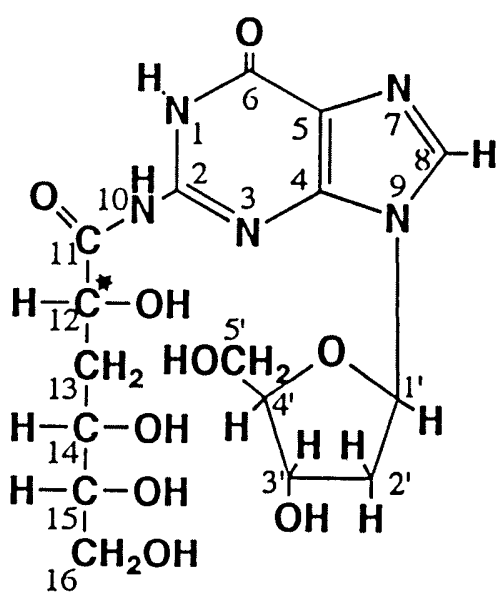

Fig. 10. Structures of G-A and G-B. *: asymmetric carbon 
hexyl)-2'-deoxyguanosine (Fig. 10). G-B was identified as a diastereomer of G-A. Moreover, two major AGEs were identified from the 3DG-DNA reaction system.

\section{2-6. Melanoidins}

Melanoidins, which are final products of the Maillard reaction, are nitrogen-containing polymeric substances that decompose with difficulty. Human beings consume melanoidins daily in browning foods. The formation mechanism of melanoidins is complex because many reactants, such as deoxyosones, osones, unsaturated osones, furfurals, pyrralines, carbonyl compounds and amino compounds are involved (Hayase et al., 1986; Hayashi \& Namiki, 1986a; Namiki, 1988; Hayase \& Kato, 1994; Friedman, 1996). The formation of melanoidins is believed to be affected by various factors such as types of reducing sugars and amino compounds, their concentrations, types of catalysts and buffers, reaction temperatures and time, $\mathrm{pH}$, water activity and presence of oxygen and metals.

Under neutral to alkaline $\mathrm{pH}$, melanoidins have reportedly formed via pyrazinium radicals by cleavage of compounds composed of two or three carbons by splitting of reducing sugars (Hayashi \& Namiki, 1986a, 1986b). Under neutral to acidic pH, deoxyosones, osones and furfurals are considered to be involved in the formation of melanoidins, which were observed from the formation of cleaved products under alkaline conditions. Also observed were heterocyclic compounds containing six carbons derived from glucose under acidic conditions. The products were

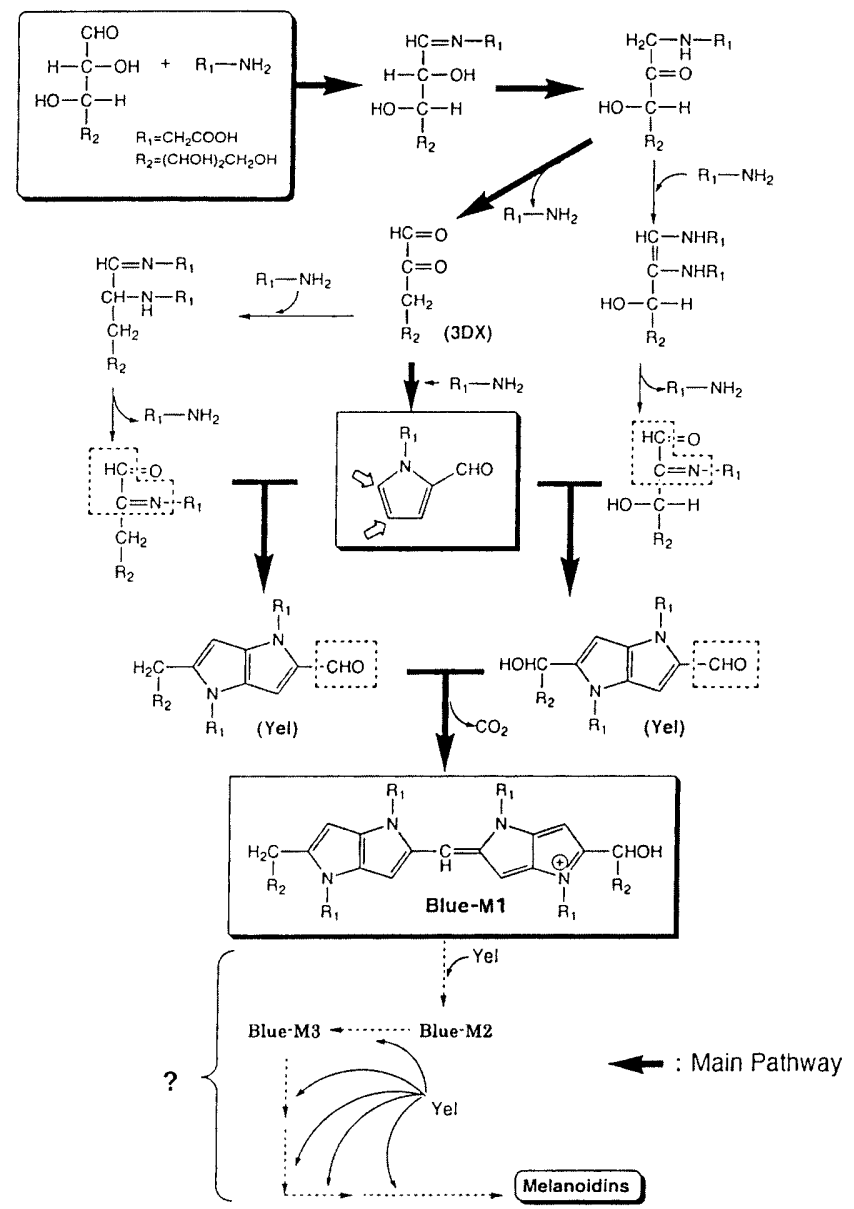

Fig. 11. Proposed formation pathway for blue compounds and melanoidins. 3DX: 3-deoxyxylosone, Yel: Yellow pigments. obtained under neutral $\mathrm{pH}$, using glucose-butylamine reaction systems (Hayase \& Kato, 1986; 1994).

Melanoidins are high-molecular weight compounds showing normal absorption and having no maximum absorption in the UV-visible region. Lignin, tannins, melanins, caramels and humins are organic compounds which are generally classified as poikilopolymers, and are difficult to identify because of the polydisperse system effect on molecular weight and electric properties (Piattell, 1961; Gomyo \& Miura, 1983).

Evidence that molecules of melanoidins are distributed as a polydisperse system has been studied. Homma et al. (1982) detected 14 bands of melanoidins obtained from the reaction system of glucose and glycine by isoelectric electrophoresis at $\mathrm{pH}$ 2.7-3.3. O'Reilly (1983) reported 20 bands at $\mathrm{pH} 2.5-4.0$ and 16 bands at $\mathrm{pH} 4.0-6.0$ in Maillard reaction products formed from xylose and glycine.

Postulated structures of brown pigments have recently been proposed. Tressl's group has reported that pyrrole polymers are formed in the 2-deoxy-D-ribose and methyl 4-aminobutyrate Maillard system (Tressl et al., 1998a). They also reported that $N$ substituted pyrrole, 2-furaldehyde, and $\mathrm{N}$-substituted 2-formylpyrroles, formed in pentose and hexose Maillard reaction systems, were identified as components of extraordinary polycondensation activity (Tressl et al., 1998b). Hofmann reported that some novel red-brown and red compounds were identified by Maillard reaction of bound arginine with glyoxal and furan-2carboxaldehyde (Hofmann, 1998a), pentoses and primary amino acids (Hofmann, 1998b), and hexoses and primary or secondary amino acids (Hofmann, 1998c). However, these colored compounds have less hydrophilic properties, indicating significant differences in hydrophilic properties of melanoidins.

Miura and Gomyo (1982), and Gomyo et al. (1989) have found the formation of blue pigments in the Maillard reaction of D-xylose and glycine. The blue pigment designated Blue-M1 (blue Maillard reaction intermediate-1) is postulated to be an intermediate oligomer in the generation of melanoidins as shown in Fig. 11 (Hayase et al., 1999); it is assumed to be a dimer of yellow colored pyrrolopyrrole-2-carboxaldehyde compounds. Blue-M1 that reacts readily to yellow compounds has a polymerizing activity, suggesting it is an important Maillard reaction intermediate through the formation of melanoidins. Figure 11 shows the proposed mechanism of the formation of Blue-M1 which might be generated by the decarboxylation from two molecules of yellow pigments, possibly two condensated pyrrolopyrrole-2-carboxyaldehyde compounds between glycyl-pyrraline and 3-deoxyxylosone or xylosone. Blue-M2 is thought to be formed by the addition reaction of yellow pigment to Blue-M1. In an advanced stage of the Maillard reaction, melanoidins may be formed by such a polymerization reaction.

Melanoidins are known to have various functional properties (Hayase \& Kato, 1994; Hayase, 1996), for example photosensitive effects (Gomyo \& Miura, 1986), interaction with metal ions (Hashiba, 1986; Terasawa et al., 1991), antioxidative effects (Kim et al., 1986; Yamaguchi, 1986), antimicrobial action (Einarson \& Eriksson, 1990), dietary fiber-like action (Gomyo \& Miura, 1986), effect of enteric bacteria (Horikoshi et al., 1981) and inhibition of trypsin (Hirano et al., 1996). They also have desmutagenic effects on mutagenic heterocyclic amines (Kato et al., 1985; Lee et al., 1994) and scavenging effects on active oxy- 
gen species (Hayase et al., 1989b; Hayase et al., 1990). Thus, melanoidins display physiologically positive effects. It is expected that they show these effects in vivo in digestive organs because parts of melanoidins are absorbed through the gastrointestinal tracts of rats (Lee et al., 1992).

As mentioned above, low-molecular weight Maillard reaction products such as $\alpha$-dicarbonyls are cytotoxic and mutagenic (Hayase \& Kato, 1994; Shinoda et al., 1994). Therefore, both negative and positive effects need to be critically evaluated from the viewpoint of health.

Acknowledgements The author's studies were carried out together with Professor Hiromichi Kato at Otsuma University and many coworkers, all of whom I wish to thank for helpful discussions and for their expert works.

\section{References}

Arai, Y., Aida, K., Kishimoto, J., Kawabata, R. and Hayase, F. (2000). Identification and determination of dicarbonyl compounds produced by glycation of proteins. Nippon Nôgeikagaku Kaishi, 74, 276 (in Japanese).

Cerami, A. (1994). The role of the Maillard reaction in vivo. In "Maillard Reactions in Chemistry, Food, and Health," ed. by T.P. Labuza, G.A. Reineccius, V.M. Monnier, J. O'Brien and J.W. Baynes. The Royal Society of Chemistry, Cambridge, pp. 1-10.

Chiang, G.H. (1988). High-performance liquid chromatographic determination of $\varepsilon$-pyrrole-lysine in processed food. J. Agric. Food Chem., 36, 506-509.

Cho, R.K., Okitani, A. and Kato, H. (1986). Polymerization of proteins and impairment of their arginine residues due to intermediate compounds in the Maillard reaction. Dev. Food Sci., 13, 439-448.

Dyer, D.G., Blackledge, J.A., Thorpe, S.R. and Baynes, J.W. (1991). Formation of pentosidine during nonenzymatic browning of proteins by glucose. J. Biol. Chem., 266, 11654-11660.

Együd, L.G. and Szent-Györgyi, A. (1966). On the regulation of cell division. Proc. Natl. Acad. Sci. U.S.A., 56, 203-207.

Einarson, H. and Eriksson, C. (1990). The antibacterial effect of Maillard reaction products and sorbic acid at different $\mathrm{pH}$ levels and temperatures. In "The Maillard Reaction in Food Processing, Human Nutrition and Physiology," ed. by P.A. Finot, H.U. Aeschbacher, R.F. Hurrel and R. Liardon. Birkhauser Verlag, Basel, pp. 227-232.

Friedman, M. (1996). Food browning and its prevention: An overview. J. Agric. Food Chem., 44, 631-653.

Gomyo, T. and Miura, M. (1983). Melanoidin in foods: Chemical and physiological aspects. J. Jpn. Soc. Nutr. Food Sci., 36, 331-340.

Gomyo, T. and Miura, M. (1986). Effects of melanoidin on the digestion and absorption of disaccharides in the small intestine of rats Dev. Food Sci., 13, 549-558.

Gomyo, T., Haiyan, L., Miura, M., Hayase, F. and Kato, H. (1989). Kinetic aspects of the blue pigment formation in a Maillard reaction between D-xylose and glycine. Agric. Biol. Chem., 53, 949-957.

Grandhee, S.K. and Monnier, V.M. (1991). Mechanism of formation of the Maillard protein cross-link. J. Biol. Chem., 266, 11649-11653.

Hashiba, H. (1986). Oxidative browning of Amadori compounds-color formation by iron with Maillard reaction products. Dev. Food. Sci., 13, 155-164.

Hayase, F. and Kato. H. (1985). Maillard reaction products from Dglucose and butylamine. Agric. Biol. Chem., 49, 467-473.

Hayase, F. and Kato, H. (1986). Low-molecular Maillard reaction products and their formation mechanisms. Dev. Food Sci., 13, 39-48.

Hayase, F., Kim, S.B. and Kato, H. (1986). Analyses of the chemical structures of melanoidins by ${ }^{13} \mathrm{C}$ NMR, ${ }^{13} \mathrm{C}$ and ${ }^{15} \mathrm{~N}$ CP-MAS NMR spectrometry. Agric. Biol. Chem., 50, 1951-1957.

Hayase, F., Nagaraj, R.H., Miyata, S., Njoroge, F.G. and Monnier, V.M. (1989a). Aging of proteins: Immunological detection of a glucose-derived pyrrole formed during Maillard reaction. J. Biol. Chem., 264, 3758-3764.

Hayase, F., Hirashima, S. Okamoto, G. and Kato, H. (1989b). Scavenging of active oxygens by melanoidins. Agric. Biol. Chem., $\mathbf{5 3}$
$3383-3385$.

Hayase, F., Hirashima, S., Okamoto, G. and Kato, H. (1990). Scavenging of active oxygens by melanoidin. In "The Maillard Reaction in Food Processing, Human Nutrition and Physiology," ed. by P.A. Finot, H.U. Aeschbacher, R.F. Hurrel and R. Liardon. Birkhauser Verlag, Basel, pp.361-366.

Hayase, F., Liang, Z.Q., Suzuki, Y., Chuyen, N.V., Shinoda, T. and Kato, H. (1991). Enzymatic metabolism of 3-deoxyglucosone, a Maillard Intermediate. Amino Acids, 1, 307-318.

Hayase, F. and Kato, H. (1994). Maillard reaction products: Safety and physiologic effects. Comm. Agric. Food Chem., 3, 111-128.

Hayase, F., Hinuma, H., Asano, M., Kato, H. and Arai, S. (1994) Identification of novel fluorescent pyrrolopyridinium compound formed from Maillard reaction of 3-deoxyglucosone and butylamine. Biosci. Biotech. Biochem., 58, 1936-1937.

Hayase, F., Konishi, Y. and Kato, H. (1995). Identification of the modified structure of arginine residues in proteins with 3-deoxyglucosone, a Maillard reaction intermediate. Biosci. Biotech. Biochem. 59, 1407-1411.

Hayase, F. (1996). Scavenging of active oxygen by melanoidins. In "The Maillard Reaction," ed. by R. Ikan. John Wiley and Sons, Ltd. England, pp.89-104.

Hayase, F. and Takahashi, M. (1996). Maillard reaction products from 3-deoxyglucosone and butylamine under physiological conditions. Food Sci. Technol. Int., 2, 239-241.

Hayase, F., Shibuya, T., Sato, J. and Yamamoto, M. (1996). Effects of oxygen and transition metals on the advanced Maillard reaction of proteins with glucose. Biosci. Biotech. Biochem., 60, 1820-1825.

Hayase, F., Koyama, T. and Konishi, Y. (1997). Novel dehydrofuroimidazole compounds formed by the advanced Maillard reaction of 3 deoxy-D-hexos-2-ulose and arginine residues in proteins. J. Agric. Food Chem., 45, 1137-1143.

Hayase, F. and Kaneko, K. (1998). Formation of $N$-(1-oxo-2,4,5,6hydroxyhexyl)-2'-deoxyguanosine by the reaction of $2^{\prime}$-deoxyguanosine with 3-deoxyglucosone. Biosci. Biotech. Biochem., 62, $1630-1632$

Hayase, F., Nagashima, N., Koyama, T., Sagara, S. and Takahashi, Y. (1998). Reaction mechanisms operating in 3-deoxyglucosone-protein system. In "The Maillard Reaction in Foods and Medicine," ed. by J. O'Brien, H.E. Nursten, M.J.C. Crabbe and J.M. Ames. The Royal Soc. Chem.,Cambridge, pp.262-267.

Hayase, F., Takahashi, Y., Tominaga, S., Miura, M., Gomyo, T. and Kato, H. (1999). Identification of blue pigment formed in a Dxylose-glycine reaction system. Biosci. Biotech. Biochem., 63, $1512-1514$

Hayashi, T. and Namiki, M. (1986a). Role of sugar fragmentation in the Maillard reaction. Dev. Food Sci., 13, 29-38.

Hayashi, T. and Namiki, M. (1986b). Role of sugar fragmentation in an early stage browning of amino-carbonyl reaction of sugar with amino acids. Agric. Biol. Chem., 50, 1965-1970.

Henle, T. and Klostermeyer, H. (1993). Determination of proteinbound 2-amino-6-(2-formyl-1-pyrrolyl)-hexanoic acid ("pyrraline") by ion exchange chromatography and photodiode array detection. $Z$. Lebensm. Unters. Forsch., 196, 1-4.

Hirano, M., Miura, M. and Gomyo, T. (1996). Kinetic analysis of the inhibition by melanoidin of trypsin. Biosci. Biotech. Biochem., 60, $458-462$.

Hodge, J.E. (1953). Chemistry of browning reactions in model systems. J. Agric. Food Chem., 1, 928-943.

Hofmann, T. (1998a). 4-Alkylidene-2-imino-5-[4-alkylidene-5-oxo1,3-imidazol-2-inyl]azamethylidene-1,3-imidazolidine-A novel colored substructure in melanoidins formed by Maillard reactions of bound arginine with glyoxal and furan-2-carboxaldehyde. J. Agric. Food Chem., 46, 3896-3901.

Hofmann, T. (1998b). Identification of novel colored compounds containing pyrrole and pyrrolinone structures formed by Maillard reactions of pentoses and primary amino acids. J. Agric. Food Chem., 46, 3902-3911.

Hofmann, T. (1998c). Acetylformoin-a chemical switch in the formation of colored Maillard reaction products from hexoses and primary and secondary amino acids. J. Agric. Food Chem., 46, 3918- 
3928.

Homma, S., Tomura, T. and Fujimaki, M. (1982). Fractionation of nondialyzable melanoidin into components by electrofocusing electrophoresis. Agric. Biol. Chem., 46, 1791-1796.

Horikoshi, M., Ohmura, M., Gomyo, T., Kuwabara, Y. and Ueda, S. (1981). Effects of browning products on the intestinal microflora of the rat. Prog. Food Nutr. Sci., 5, 223-228.

Kato, H., Kim, S.B., Hayase, F. and Chuyen, N.V. (1985). Desmutagenicity of melanoidins against mutagenic pyrolysates. Agric. Biol. Chem., 49, 3093-3095.

Kato, H., Cho, R.K., Okitani, A. and Hayase, F. (1987a). Responsibility of 3-deoxyglucosone for the glucose-induced polymerization of proteins. Agric. Biol. Chem., 51, 683-689.

Kato, H., Shin, D.B. and Hayase, F. (1987b). 3-Deoxyglucosone crosslinks proteins under physiological conditions. Agric. Biol. Chem., 51, 2009-2011.

Kato, H., Hayase, F., Shin, D.B., Oimomi, M. and Baba, S. (1989). 3Deoxyglucosone, an intermediate product of the Maillard reaction. In "The Maillard Reaction in Aging, Diabetes, and Nutrition," ed. by J.W. Baynes and V.M. Monnier. Alan R. Liss, New York, pp. 6984.

Kim, S.B., Hayase, F. and Kato, H. (1986). Desmutagenic effects of melanoidins against amino acid and protein pyrolyzates. Dev. Food. Sci., 13, 383-392.

Knecht, K.J., Feather, M.S. and Baynes, J.W. (1992). Detection of 3deoxyglucosone in human urine and plasma: Evidence for intermediate stages of the Maillard reaction in vivo. Arch. Biochem. Biophys., 294, 130-137.

Konishi, Y., Hayase, F. and Kato, H. (1994). Novel imidazolone compound formed by the advanced Maillard reaction of 3-deoxyglucosone and arginine residues in proteins. Biosci. Biotech. Biochem., 58, 1953-1955.

Ledl, F. and Schleicher, E. (1990). New aspects of the Maillard reaction in foods and in the human body. Angew. Chem. Int. Ed. Engl., 29, 565-594.

Lee, I.E., Chuyen, N.V., Hayase, F. and Kato, H. (1992). Absorption and distribution of $\left[{ }^{14} \mathrm{C}\right]$ melanoidins in rats and the desmutagenicity of absorbed melanoidins against Trp-P-1. Biosci. Biotech. Biochem., 56, 21-23.

Lee, I.E., Chuyen, N.V., Hayase, F. and Kato, H. (1994). Desmutagenicity of melanoidins against various kinds of mutagens and activated mutagens. Biosci. Biotech. Biochem., 58, 18-23.

Miura, M. and Gomyo, T. (1982). Formation of blue pigment in the earlier stage of browning in a system composed of D-xylose and glycine. Nippon Nôgeikagaku Kaishi, 56, 417-425 (in Japanese).

Miyata, S. and Monnier, V.M. (1992). Immunohistochemical detection of advanced glycosylation end products in diabetic tissues using monoclonal antibody to pyrraline. J. Clin. Invest., 89, 1102-1112.

Monnier, V.M., Sell, D.R., Nagaraj, R.H. and Miyata, S. (1991). Mechanisms of protection against damage mediated by the Maillard reaction in aging. Gerontology, 37, 152-165.

Monnier, V.M., Sell, D.R., Nagaraj, R.H., Miyata, S., Grandhee, S. Odetti, P. and Ibrahim, S.A. (1992). Maillard reaction-mediated molecular damage to extracellular matrix and other tissue proteins in diabetes, aging, and uremia. Diabetes, 41, 36-41.

Nakamura, K., Hasegawa, T., Fukunaga, Y. and Ienaga, K. (1992). Crosslines $\mathrm{A}$ and $\mathrm{B}$ as candidates for the fluorofores in age- and diabetes-related cross-linked proteins, and their diabetes produced by Maillard reaction of $\alpha-\mathrm{N}$-acetyl-L-lysine with D-glucose. J. Chem. Soc. Chem. Commun., 992-994.

Nakayama, T., Hayase, F. and Kato, H. (1980). Formation of $\varepsilon-(2-$ formyl-5-hydroxymethyl-pyrrol-1-yl)-L-norleucine in the Maillard reaction between D-glucose and L-lysine. Agric. Biol. Chem., 44 1201-1202

Namiki, M. (1988). Chemistry of Maillard reaction: Recent studies on the browning reaction mechanism and the development of antioxidants and mutagens. Adv. Food Res., 32, 135-184.

Niwa, T., Takeda, N., Yoshizumi, H., Tatematsu, A., Ohara, M., Tomiyama, S. and Niimura, K. (1993). Presence of 3-deoxyglucosone, A potent protein crosslinking intermediate of Maillard reaction, in dia- betic serum. Biochem. Biophys. Res. Commun., 196, 837-843.

Niwa, T., Katsuzaki, T., Miyazaki, S., Momoi, T., Akiba, T., Miyazaki, T., Nokura, K., Hayase, F., Tatemichi, N. and Takei, Y. (1997a) Amyloid $\beta_{2}$-microglobulin is modified with imidazolone, a novel advanced glycation end product, in dialysis-related amyloidosis. Kidney Int., 51, 187-194.

Niwa, T., Katsuzaki, T., Miyazaki, S., Miyazaki, T., Ishizaki, Y., Hayase, F., Tatemichi, N. and Takei, Y. (1997b). Immunohistochemical detection of imidazolone, a novel advanced glycation end product, in kidneys and aortas of diabetic patients. J. Clin. Invest., 99 $1272-1280$

Niwa, T., Katsuzaki, T., Ishizaki, Y., Hayase, F., Miyazaki, T., Uematsu, T., Tatemichi, N. and Takei, Y. (1997c). Imidazolone, a novel glycation end product, is present at high levels in kidneys of rats with streptozotocin-induced diabetes. FEBS Lett., 407, 297-302.

Niwa, T. (1999). 3-Deoxyglucosone: Metabolism, analysis, biological activity, and clinical implication. J. Chromatogr. B, 731, 23-36.

O'Reilly, R. (1983). Application of electrofocusing for the fractionation of colored products formed during the xylose-glycine Maillard reaction. Chem. Ind., 19, 716-717.

Papoulis, A., Al-Abed, Y. and Bucala, R. (1995). Identification of $N^{2}$ (1-carboxyethyl)-guanine (CEG) as a guanine advanced glycosylation end product. Biochemistry, 34, 648-655.

Piattell, M. (1961). The structure of melanins and melanogenesis-I The structure of melanin in SEPIA. Tetrahedron, 15, 66-75.

Portero-Otin, M., Nagaraj, R.H. and Monnier, V.M. (1995). Chromatographic evidence for pyrraline formation during protein glycation in vitro and in vivo. Biochim. Biophys. Acta, 1247, 74-80.

Prabhakaram, M. and Mossine, V.V. (1998). Characterization of a blue fluorophore isolated from in vitro reaction of $\mathrm{N}-\alpha$-acetyllysine and 3-deoxyglucosone. Prep. Biochem. Biotechnol., 28, 319-338.

Resmini, P. and Pellegrino, L. (1994). Occurrence of protein-bound lysylpyrrolaldehyde in dried pasta. Cereal Chem., 71, 254-262.

Sell, D.R. and Monnier, V.M. (1989). Structure elucidation of a senescence cross-link from human extracellular matrix. J. Biol. Chem., 264, 21597-21602.

Shin, D.B., Hayase, F. and Kato, H. (1988). Polymerization of proteins caused by the reaction with sugars and the formation of 3-deoxyglucosone under physiological conditions. Agric. Biol. Chem., 52, 1451-1458.

Shinoda, T., Hayase, F. and Kato, H. (1994). Suppression of cell-cycle progression during the $\mathrm{S}$ phase of rat fibroblasts by 3-deoxyglucosone, a Maillard reaction intermediate. Biosci. Biotech. Biochem., 58, 2215-2219.

Szent-Györgyi, A., Egyuid, L.G. and McLaughlin, J.A. (1967). Ketoaldehydes and cell division. Science, 155, 539-541.

Szwergold, B.S., Kappler, F. and Brown, T.R. (1990). Identification of fructose 3-phosphate in the lens of diabetic rats. Science, 247, 451454 .

Terasawa, N., Murata, M. and Homma, S. (1991). Separation of model melanoidin into components with copper chelating Sepharose 6B column chromatography and comparison of chelating activity. Agric. Biol. Chem., 55, 1504-1514.

Tressl, R., Wondrak, G.T., Krüger, R-P. and Rewicki, D. (1998a). New melanoidin-like Maillard polymers from 2-deoxypentoses. J. Agric. Food Chem., 46, 104-110.

Tressl, R., Wondrak, G.T., Garbe, L-A., Krüger, R-P. and Rewicki, D (1998b). Pentoses and hexoses as sources of new melanoidin-like Maillard polymers. J. Agric. Food Chem.,46, 1765-1776.

Wells-Knecht, K.J., Zyzak, D.V., Litchfield, J.E., Thorpe, S.R. and Baynes, J.W. (1995). Mechanism of autoxidative glycosylation: Identification of glyoxal and arabinose as intermediates in the autoxidative modification of proteins by glucose. Biochemistry, 34, 3702-3709

Yamada, H., Miyata, S., Igaki, N., Yatabe, H., Miyauchi, Y., Ohara, T., Sakai, M., Shoda, H., Oimomi, M. and Kasuga, M. (1994). Increase in 3-deoxyglucosone levels in diabetic rat plasma. J. Biol. Chem., 269, 20275-20280.

Yamaguchi, N. (1986). Antioxidative activity of the oxidation products prepared from melanoidins. Dev. Food Sci., 13, 291-299. 